Revista do Corpo Discente do Programa de Pós-Graduação em História da UnB

Em TEMPO DE HISTÓRIAS | Brasília-DF | n. 36 | p. 504-526 | jan./jun. 2020.

ISSN 2316-1191

This work is licensed under a Creative Commons Attribution-NonCommercial 4.0 International License.

Recebido em 24/05/2020

Aceito em 26/06/2020

DOI: $10.26512 /$ emtempos.v1i36.31751

\title{
DOSSIÊ \\ Apontamentos sobre o apagamento da população negra no relatório da Comissão Nacional da Verdade - 2014
}

\author{
Notes about the black population's erasure \\ in the National Truth Commission's report - 2014
}

\author{
Tairane Ribeiro da Silva \\ Doutoranda em História na UFRGS \\ tairanee@yahoo.com.br
}

\begin{abstract}
RESUMO: A Comissão Nacional da Verdade, instaurada pela Lei n. ${ }^{0} 12.528$ em junho de 2012 com a tarefa de apurar os casos de violações de direitos humanos sofridas na época da ditadura civil-militar brasileira (1964-1964) efetivando o "direito à memória e a verdade histórica e promover a reconciliação nacional". Após o trabalho finalizado pela CNV, foi entregue a sociedade em 10 de dezembro de 2014 o relatório final das atividades onde os resultados apresentados ao final das atividades mostrou um apagamento sobre a problematização da população negra na ditadura civil-militar brasileira, portanto devido a esta ausência, a proposta deste artigo é visibilizar as vítimas negras e negros que constam no número final de mortos e desaparecidos pela ditadura no relatório final da CNV abordando seus perfis, atuação profissional, organizações políticas as quais participavam, além de apresentar alguns debates em torno da situação da população negra no período.
\end{abstract}

PALAVRAS-CHAVE: Comissão Nacional da Verdade. Ditadura Civil-Militar. População Negra.

\begin{abstract}
The National Truth Commission, established by Law no. 12,528 in June 2012 with the task of investigating cases of human rights violations suffered at the time of the Brazilian civil-military dictatorship (1964-1964) by implementing the "right to memory and historical truth and promoting national reconciliation. After the work finalized by the CNV, society was delivered on December 10, 2014 the final report of activities where the results presented at the end of the activities showed an erasure about the problematization of the black population in the Brazilian civil-military dictatorship, therefore due to this absence, the proposal of this article is to make visible the black and black victims who appear in the final number of deaths and disappearances by the dictatorship in the final report of the CNV addressing their profiles, professional performance, political organizations in which they participated, in addition to presenting some debates around the situation of the black population in the period.
\end{abstract}

KEYWORDS: National Truth Commission.Civil-Military Dictatorship.Black Population. 
Revista do Corpo Discente do Programa de Pós-Graduação em História da UnB

Em TEMPO dE HISTÓRIAS | Brasília-DF | n. 36 | p. 504-526 | jan./jun. 2020.

ISSN 2316-1191

\section{Introdução}

O primeiro contato que tive com a temática da ditadura civil-militar, foi na graduação em Licenciatura em História, através de duas experiências importantes para minha carreira: cursar a disciplina de História do Brasil Contemporâneo, onde uma das temáticas tratadas era a ditadura e participar de debates sobre o período em grupos de estudos. Em ambos os espaços, a ditadura aparece como um "acontecimento" de pessoas brancas. Logo, contextualizar a população negra no período se torna fundamental, visto que o racismo institucional atingiu as dinâmicas da ditadura e ainda se apresenta de forma ativa na trajetória dessa população. Uma intelectual negra, chamada Lélia Gonzalez, trouxe muitas contribuições para pensar a população negra e a mulher negra no Brasil. González foi professora, filósofa, antropóloga e uma das idealizadoras do Movimento Negro Unificado em 1978, contribuindo sociologicamente para compreender as diversas formas que o Brasil da ditadura civil-militar tratava a população negra de forma geral:

\footnotetext{
Um dos mecanismos mais cruéis da situação do negro brasileiro na força de trabalho concretiza-se na sistemática perseguição, opressão e violência policiais que contra ele se desenvolvem. Quando seus documentos são solicitados (fundamentalmente a carteira profissional) e se constata que está desempregado, o negro é preso por vadiagem; em seguida, é torturado (e muitas vezes assassinado) e obrigado a confessar crimes que não cometeu. De acordo com a visão dos policiais brasileiros, "todo negro é um marginal (thief) até prova em contrário". Claro está, que esse consenso setorial não é uma casualidade (GONZALEZ, 1979, p.1).
}

É evidente, portanto, que a oposição ao golpe civil-militar no país não se resumiu apenas ao âmbito das classes ricas e médias, majoritariamente brancas. É possível perceber que também ocorreu a presença e resistência da população pobre e negra nesse movimento de confronto contra a ditadura que estava instaurada no Brasil. Essa parcela de brasileiros e brasileiras foi a que mais sofreu com as políticas autoritárias e de repressão do período, podendo localizar que entre os mortos e desaparecidos da ditadura civil-militar, temos nomes de militantes de origem negra, embora pouco se tenha conhecimento deles, por conta de um apagamento de fontes ou silenciamento de suas histórias. Alguns destes militantes negros e negras constam na lista oficial de mortos e desaparecidos pela ditadura civil-militar brasileira apurada e divulgada pela Comissão Nacional da Verdade. Afinal, o que foi a Comissão Nacional da verdade?

O longo período de silêncio sobre os crimes cometidos pelo Estado durante o período militar perdurou na sociedade brasileira por quase três décadas a partir de pactos firmados na "Nova República". A criação de uma Comissão da Verdade traria a tona, portanto, um trauma social inconcluso na sociedade brasileira que por conta da censura muitos desconheciam (FICO, 2012). Logo, a 
Revista do Corpo Discente do Programa de Pós-Graduação em História da UnB

Em TEMPO dE HISTÓRIAS | Brasília-DF | n. 36 | p. 504-526 | jan./jun. 2020.

ISSN 2316-1191

criação da Comissão da Verdade, teria a função de responsabilizar todos os envolvidos nos casos de repressão e violação de direitos humanos no período entre 1946 e 1988. Portanto, é reconhecida a memória e a verdade como direito humano da cidadania e dever do Estado, a partir das propostas aprovadas no Plano Nacional de Direitos Humanos - PNDH - 3 em 2008 e 2009 (GASPAROTTO, 2013). Da fundação da PNDH - 3 em diante, disputas e controvérsias fizeram parte da discussão, pois um lado corroborou com as propostas aprovadas pelo plano, e o outro, formou uma camada conservadora das Forças Armadas, que defenderam a necessidade de uma investigação dos "dois lados", ou seja, os crimes cometidos pelo Estado e os crimes cometidos pela esquerda (GASPAROTTO, 2013).

A Comissão Nacional da Verdade foi empossada em 16 de maio de 2012, composta por sete membros escolhidos pela Presidência da República. Seu relatório final foi lançado no dia 10 de dezembro de 2014, no governo da presidente Dilma Rousseff, em solenidade no Palácio do Planalto. O trecho a seguir descreve bem o objetivo da criação da comissão nacional da verdade:

A criação da Comissão Nacional da Verdade assegurará o resgate da memória e da verdade sobre as graves violações de direitos humanos ocorridas no período anteriormente mencionado [1946-1988], contribuindo para o preenchimento das lacunas existentes na história de nosso país em relação a esse período e, ao mesmo tempo, para o fortalecimento dos valores democráticos. ${ }^{1}$

Embora o compromisso da Comissão tenha sido de "preenchimento de lacunas existentes na história de nosso país", a produção do relatório evidência uma invisibilidade de histórias de negras e negros que estavam em atividade contra a ditadura, bem como a origem de suas organizações, associações culturais e etc. Logo, ressalto que a temática racial é um fator crucial para que possamos compreender essas militâncias e os fatores que os motivavam no período da ditadura. Na contramão da invisibilidade do relatório, é possível perceber um crescimento de debates sobre as questões raciais no Brasil, fruto das políticas de ações afirmativas em universidades federais.

Portanto, o objetivo desse artigo, é fazer um levantamento de dados de mortos e desaparecidos negros que constam no relatório. Por conta da Comissão não tratar de uma forma ramificada esta questão, pretendo traçar um perfil desses militantes, pontuando suas atuações profissionais, as organizações políticas e dados complementares.

\footnotetext{
1 Mensagem de 12 de maio de 2010 do presidente da República, Luiz Inácio da Silva, ao Congresso Nacional, encaminhando o projeto de lei de criação da Comissão Nacional da Verdade.
} 
Revista do Corpo Discente do Programa de Pós-Graduação em História da UnB

Em TEMPO dE HISTÓRIAS | Brasília-DF | n. 36 | p. 504-526 | jan./jun. 2020.

ISSN 2316-1191

\section{O relatório final da Comissão Nacional da Verdade, sua estruturação e alguns apontamentos}

O relatório da Comissão Nacional da Verdade conta com três grandes tomos. O primeiro tomo possui um caráter introdutório, contando como aconteceu a criação da Comissão Nacional da Verdade, sua formação, a equipe integradora, seu relacionamento com órgãos judiciais, civis e forças armadas, além de abordar o funcionamento de Comissões da Verdade de outros países que passaram por períodos de exceção. $\mathrm{O}$ segundo tomo ficou encarregado de apresentar os textos temáticos, com a proposta de apresentar um contexto histórico do período de 1946 a 1988, bem como apresentar os órgãos do Estado que contribuíram para o fortalecimento da ditadura, os diferentes métodos de repressão e práticas de violação de direitos humanos. Logo após, foi dedicado um capítulo para cada setor da sociedade civil que sofreu graves violações de direitos humanos, intitulados como "Casos emblemáticos". Contudo, a falha se dá ao fato da Comissão Nacional da Verdade não ter abordado a população negra brasileira da época como um dos "casos emblemáticos" da ditadura civil-militar, da mesma forma que tratou com os camponeses, os indígenas, etc. O/a negro/a é citado nas entrelinhas no eixo temático "Ditadura e Homossexualidades". em conjunto com as mulheres, onde aborda:

Usar conceitos como "minorias" para caracterizar genericamente grupos vulneráveis que foram alvos de repressão e de opressão, tais como as mulheres, os negros e os homossexuais, atribuindo-lhes papéis marginais na conquista da democracia, é reproduzir uma leitura da época da ditadura. Pelos critérios mais aceitos, neste país, as mulheres são uma maioria e os negros também.(COMISSÃO NACIONAL DA VERDADE, 2014,p.301).

Embora a temática não tenha sido vista com zelo pela Comissão, algumas Comissões Estaduais, como a Comissão da Verdade do Estado de São Paulo Rubens Paiva, dedicaram uma parte do seu relatório para um eixo temático intitulado "Perseguição a População e ao Movimento Negro". Nele, abordou como a população negra e o movimento negro resistiam á ditadura de diversas formas, a partir da arte e da música, além de apresentar também uma lista de mortos/as e desaparecidos/as negros/as paulistas.

Já o livro-relatório "Aos descendentes de homens e mulheres que cruzaram o oceano a bordo de navios negreiros e foram mortos na luta contra o regime militar", editado pela Secretaria Especial dos Direitos Humanos da Presidência da República, de 2007, traz especialmente a contextualização da trajetória das/os militantes negras/os em colaboração dos familiares das vítimas que concederam seus relatos para a construção do livro-relatório. Estes familiares foram devidamente indenizados pelo Estado e a criação deste livro-relatório contou com o apoio da Secretaria Especial de Políticas de Promoção da Igualdade Racial (SEPPIR) do governo do presidente Lula.

O Terceiro Tomo da Comissão Nacional da Verdade, o último tomo do relatório, ficou com a tarefa de apresentar a lista dos mortos e desaparecidos de 
Revista do Corpo Discente do Programa de Pós-Graduação em História da UnB

Em TEMPO dE HISTÓRIAS | Brasília-DF | n. 36 | p. 504-526 | jan./jun. 2020.

ISSN 2316-1191

1950 a 1985 em ordem alfabética ou por ano, conforme consta disponível na plataforma da Comissão Nacional da Verdade, no site oficial do governo federal. Nele contém informações de cada vítima com nome completo, fotografia, filiação, ocupação, organização política a qual participava (caso participasse), data de nascimento, data e local da morte ou desaparecimento, além de uma breve biografia da vítima, causa da morte e uma conclusão e recomendação da Comissão Nacional da Verdade para cada caso. O ponto importante para este artigo foi constatar por vezes uma ausência ou uma confusão da cor/raça de algumas vítimas presentes na listagem.

Intelectuais que produziram bibliografia durante a ditadura e sobre o período como Lélia Gonzalez e Abdias do Nascimento já denunciavam em suas obras a violência policial contra a população negra, a questão do racismo e a "pacificação" que o Estado fazia para manter a pátria brasileira em ordem, pois preto sem documento era considerado marginal e por consequência era eliminado sem qualquer direito de defesa (GONZALEZ, 1982). Logo, as reflexões abordadas neste artigo surgem ao analisar os aspectos do Tomo II do relatório final, que ao tratar de "casos emblemáticos" optou por não considerar na Comissão Nacional da Verdade a abordagem da população negra no país.

\title{
"O terror nosso de cada dia": a ditadura civil-militar e a população negra
}

\begin{abstract}
Em junho, num encontro do Movimento Negro da Baixada Fluminense, justamente a respeito da violência policial, foram apresentados os seguintes dados a respeito dos corpos de "justiçados" que deram entrada no Instituto Médico Legal de Nova Iguaçu, no período entre 01/01 a 31/01: 305 brancos, 635 negros e 170 não identificados. E todos sabem que uma verdadeira guerra de extermínio instaurou-se de 15 de março para cá e da qual nem nossas crianças negras escapam. Quatro delas feridas no morro da Mangueira e, para culminar, o assassinato brutal, com um tiro na testa, de Estela Márcia dos Santos, 13 anos, no morro do Tuiuti. "É a polícia do Moreira", diz o povão. (GONZALEZ, 1978, p.8)²
\end{abstract}

Muitos fatores influenciaram para que a ditadura civil-militar brasileira alcançasse êxito e para entender este processo é fundamental abordar causas que contribuíram para a consolidação do golpe no país. A renúncia de Jânio Quadros $^{3}$ mudou toda a conjuntura do país e a posse de seu vice gerou um descontentamento na direita brasileira da época que baseada nas tradições

\footnotetext{
2 Retirado do artigo de Lélia Gonzalez ( 01/2/1935-10/7/1994), divulgado no jornal Raça \& Classe ( Brasília, ano 1, $\mathrm{n}^{0}$ 2,ago./set. de 1987, p.8). e disponível online em http://www.meionorte.com/blogs/edilsonnascimento/o-terror-nosso-de-cada-dia-lelia-viva-leiaartigo-de-1987-sobre-a-violencia-no-rio-76476.

3 Empossado em 31 de janeiro de 1961.
} 
Revista do Corpo Discente do Programa de Pós-Graduação em História da UnB

Em TEMPO dE HISTÓRIAS | Brasília-DF | n. 36 | p. 504-526 | jan./jun. 2020.

ISSN 2316-1191

liberais, autoritárias e conservadoras enxergou o projeto político de João Goulart ${ }^{4}$ como uma ameaça, por apresentar um projeto político alicerçado em pautas como inclusão social, reforma agrária, democratização sendo visto como um político populista, aspectos que chamavam atenção da camada conservadora por conta do medo da ameaça comunista, discurso fortalecido com o contexto de Guerra Fria, que só ampliou mais a crise política em seu governo (NAPOLITANO 2014).

Com os militares tentando impedir a posse de Jango de todas as maneiras em conjunto com o Congresso Nacional e a camada civil, Leonel Brizola, na época governador do Estado do Rio Grande do Sul, organizou a Campanha da Legalidade $^{5}$ foi uma mobilização que reuniu civis e militares em favor da manutenção da ordem jurídica no país após a posse de Jango. No trecho do livro "Ditadura militar e democracia no Brasil: História, Imagem e Testemunho" nos traz o seguinte contexto sobre o impacto da Campanha da Legalidade

\begin{abstract}
Greves explodiram em várias capitais exigindo o cumprimento da Constituição e a posse de João Goulart. A mudança do regime presidencialista para parlamentarista foi a solução encontrada na época para resolver o impasse criado pelo veto militar. Esta solução - que permitia a posse de Jango com menos poder - foi articulada entre alguns ministros do governo, militares, o Congresso Nacional e o próprio Jango. Jango assumiu a presidência no dia 7 de setembro de 1961. ( ARAUJO;SILVA;SANTOS, 2013,p.11)
\end{abstract}

A camada social conservadora mobilizou-se contra o governo de João Goulart com a Marchas da Família com Deus pela Liberdade ${ }^{6}$, que foi um dos episódios mais marcantes de mobilização social na época que levou milhões de pessoas de todas as classes sociais para as ruas (REIS, 2013). Logo todas as estratégias políticas não foram suficientes para manter o presidente no seu cargo e em 31 de março de 1964 o presidente foi deposto por um golpe de Estado, iniciando a ditadura civil-militar brasileira. A ditadura foi marcada por inúmeros Atos Institucionais, repressões das mais diversas, censuras, mortes e desaparecimentos de pessoas que se posicionaram contra todas as truculências do autoritarismo que teve duração de 21 anos. Compreende-se que ao discutir a ditadura civil-militar significa tocar numa história recente do nosso país, marcada por dor e lacunas em aberto e principalmente marcada por busca de memória, verdade e justiça aos/as mortos/as e desaparecidos/as políticos/as. Por se tratar de um evento traumático na história recente do Brasil, é difícil sanar lacunas historiográficas do período sem trazer o desconforto social, logo "As

\footnotetext{
${ }^{4}$ Governo que se concretiza após Jânio Quadros renunciar seu cargo de Presidente da República em agosto de 1961. João Goulart por ser seu vice, possuía a legitimidade em assumir o cargo de Presidente da República.

${ }^{5}$ Leonel Brizola adquiriu uma estação de rádio e formou uma cadeia de 50 estações de rádio por todo o país - a Rede da Legalidade.

6 "A primeira marcha realizou-se em São Paulo, em 19 de março de 1964, reunindo cerca de meio milhão de pessoas. Foi convocada em reação ao Comício pelas Reformas que teve lugar uma semana antes, no Rio de Janeiro, com 350 mil pessoas." (REIS, 2013,p.197).
} 
Revista do Corpo Discente do Programa de Pós-Graduação em História da UnB

Em TEMPO dE HISTÓRIAS | Brasília-DF | n. 36 | p. 504-526 | jan./jun. 2020.

ISSN 2316-1191

dificuldades de enunciação dos eventos traumáticos são correlatas à dos episódios delicados ou tabus, mas aqui sobressai uma questão importante. Tais dificuldades, tantas vezes mencionadas, dizem respeito, sobretudo, às vítimas." (FICO, 2014, p.252).

O recurso de governos autoritários e ditatoriais é trabalhar com a repressão e violenta e na ditadura brasileira não foi diferente. Pessoas, ideias, manifestações políticas e culturais que colocassem a "pátria" e a "paz" em risco ou questionamento era penalizado. O terrorismo de Estado, seria um mecanismo que o Estado possuía para tentar manter a ordem em seu território. Segundo (PADRÓS, 2014) a função do terrorismo de estado era propagar o medo generalizado na sociedade, consolidar uma figura do "inimigo interno", seja este inimigo apresentado em forma física, corpórea na figura de algum líder da militância, seja um movimento político, manifestação cultural, tudo que apresentava-se contrário aos ideais e objetivos da ditadura brasileira, passaria a ser alvo de eliminação do Estado.

Nesse sentido a repressão alcançou todas e todos que contestavam as normas regidas pelo Estado, ou seja, contestar representava ameaçar a ordem social estabelicida. Porém quando se pensa nas vítimas, qual é o perfil que vem a nossa cabeça? Qual o perfil de militantes, de sociedade, a historiografia nos apresenta? Pessoas brancas, de classe social privilegiada, na maioria das vezes. Ao abordar esses questionamentos, creio que seja possível questionar a historiografia já produzida e também como forma de elucidar que todas/os com suas particularidades sobreviveram e resistiram a ditadura civil-militar brasileira. Por isso, julgo é fundamental racializar estas pessoas, negras/aos e brancas/os porque a cor da pele os diferenciou nas abordagens da ditadura como a autora Lélia Gonzalez descreve de que forma diretrizes e mudanças da ditadura civil-militar atingiram especialmente a população negra

\footnotetext{
O golpe militar de 1964 procurou estabelecer uma "nova ordem" na sociedade brasileira já que, de acordo com aqueles que o desencadeiam "o caos, a corrupção e o comunismo" ameaçavam o país. Tratou-se, do estabelecimento de mudanças na economia mediante a criação do que foi chamado de um novo modelo econômico em substituição ao anterior. Mas para que isso se desse, os militares determinaram que seria necessário impor a "pacificação" da sociedade civil. E a gente sabe o que significa esse termo, pacificação, sobretudo na história de povos como o nosso: o silenciamento, a ferro e fogo, dos setores populares e de sua representação política. Ou seja, quando se lê "pacificação", entenda-se repressão. (GONZALEZ, 1982, p.11)
}

A autora faz uma contextualização do que foi o período para a população negra na questão econômica, com relação à repressão do estado. $O$ milagre econômico vivido nos anos 1970, que é muito falado até hoje, foi sentido de maneiras diferentes pelas classes sociais brasileiras. As massas, que eram majoritariamente constituídas por pessoas negras, fora a parcela que viveu a parte do empobrecimento desse milagre econômico. Logo aos negros persistiam 
Revista do Corpo Discente do Programa de Pós-Graduação em História da UnB

Em TEMPO dE HISTÓRIAS | Brasília-DF | n. 36 | p. 504-526 | jan./jun. 2020.

ISSN 2316-1191

profissões com mão de obra barata ou que não exigiam qualificação para exercer a função.

Outro grande escoadouro de mão-de-obra barata foi a prestação de serviço. Também ali encontramos o trabalhador negro fortemente representado, sobretudo em atividades menos qualificadas tais como limpeza urbana, serviços domésticos, correios, segurança, transportes urbanos, etc.(GONZALEZ, 1982,p.14)

Com relação à repressão policial, dado seu caráter racista o objetivo era próximo a imposição de uma submissão psicológica através do medo. O discurso ideológico de manter a ordem e a segurança social, só legitimou a ação policial com seus esquadrões da morte ${ }^{7}$ em cima da população negra. No livro "Lugar de Negro", Gonzalez fala do fenômeno que ocorreu na Baixada Fluminense, por conta do grande número de pessoas que migraram para essa região, consequência do milagre econômico citado acima. Portanto ela comenta neste trecho a violência policial sofrida na região

[...] Seus habitantes logo se acostumaram a um novo componente de paisagem: os "presuntos" (cadáveres) "desovados" pelos "justiceiros" da nova ordem. Vale notar que $70 \%$ desses "justiçados" eram negros. Discriminação racial? Era proibido falar dessas coisas naqueles anos de "milagre", uma vez que se estaria ferindo a Lei de Segurança Nacional por crime de subversão. (GONZALEZ, 1982, p.17).

Percebe-se que o estado utiliza de aparato político, ideológico e institucional para legitimar suas práticas de repressão sob um determinado grupo étnico. Logo o racismo nada mais é do que um conteúdo de dominação política e ideológico que se alimenta de ambições políticas para justificar todos os crimes em nome desse direito (MOURA 1994). O autor Carlos Moore apresenta a simplicidade do racismo ao se perpetuar nas sociedades ao longo da história acontece por conta do fenótipo, baseado em três dinâmicas

a) a fenotipização de diferenças civilizatórias e culturais; b) a simbologização da ordem fenotipizada por meio da transferência do conflito concreto para a esfera do fantasmático (isso implica fenômenos como a demonização das características fenotípicas do vencido em detrimento da exaltação das características do segmento populacional vencedor); e c) o estabelecimento de uma ordem social baseada numa hierarquização raciológica, mediante a subordinação política e socioeconômica permanente do mundo populacional conquistado. (MOORE, 2007, p. 247)

\footnotetext{
7 “[...] Surgiu no Rio de Janeiro, no período entre o final dos anos 1950 e início dos anos 1960. Tratava-se de grupos de policiais envolvidos com a criminalidade. Segundo a jurista e pesquisadora Alessandra Teixeira, em depoimento à Comissão da Verdade do Estado de São Paulo "Rubens Paiva", os envolvidos agiam em prol de diversos interesses, com ligações diretas com as economias criminais, como, por exemplo, o jogo do bicho, a prostituição e também o tráfico de entorpecentes, além de torturas e assassinatos." Disponível em: http://comissaodaverdade.al.sp.gov.br/relatorio/tomo-i/parte-i-cap2.html
} 
Revista do Corpo Discente do Programa de Pós-Graduação em História da UnB

Em TEMPO dE HISTÓRIAS | Brasília-DF | n. 36 | p. 504-526 | jan./jun. 2020.

ISSN 2316-1191

Pós o contexto do período em questão foi feito para abordar a questão central do artigo: a população negra na ditadura civil militar. Onde estavam às negras e os negros na ditadura? A população negra mostrou resistência ao golpe? Resistiu? Lutou? Sobreviveu? São questões c que fizeram com que este artigo se atentasse a questão de raça, justamente por raramente ter visto trabalhos acadêmicos ligados à temática de ditadura preocupados com esta questão e por conta das lacunas que foram deixadas na versão final do Relatório da Comissão Nacional da Verdade.

Você também pode dar um presunto legal!: o perfil de negros e negras mortos/as e desaparecidos/as no relatório da Comissão Nacional da Verdade

O subtítulo utilizado "você também pode dar um presunto legal!" dá o nome de um filme produzido clandestinamente nos anos 70, que aborda a questão do Esquadrão da Morte, chefiado em São Paulo, pelo delegado Sérgio Fleury. Seu nome faz uma ironia ao apelido que os militares atuantes nesses esquadrões da morte utilizavam para apelidar seus cadáveres, em maioria homens negros. Trouxe a menção do filme como reflexão e uma provocação ao leitor para o início da abordagem do perfil do militante negra/o presente no relatório da Comissão Nacional da Verdade. Para iniciar trago dois casos bem distintos e curiosos, que vão de encontro com toda a problemática deste artigo com relação às ausências, apagamentos não apenas presentes no relatório da Comissão Nacional da Verdade, mas também em algumas produções acadêmicas e historiografias no geral.

O primeiro caso é de um homem negro, chamado Dilermano Mello do Nascimento (Imagem 1), nascido na Paraíba no dia 9 de fevereiro de 1920. Dilermano, diferente de muitos negros de sua época, teve a oportunidade de estudar em uma universidade, concluindo o curso de economia na Universidade do Distrito Federal (UDF), hoje atual Universidade Federal do Rio de Janeiro (UFRJ). Ocupava um cargo importante como diretor da Divisão de Materiais, Ministério da Justiça, nas vésperas do golpe de 1964. Logo que os militares assumiram o país, Dilermano é exonerado do cargo e passou a ser alvo de investigações em um inquérito policial militar (IPM) com a justificativa de apurar suspeitas de subversão e corrupção, além de um inquérito administrativo para averiguar supostas irregularidades na aplicação de verbas do Ministério da Justiça.

Em decorrência das ações perpetradas por agentes do Estado, Dilermano Mello do Nascimento morreu aos 44 anos de idade nas dependências do Ministério da Justiça, após ser chamado para um simples interrogatório. Nos documentos oficiais do Estado, atestam que ele se suicidou, porém a declaração da viúva de Dilermano, Natália de Oliveira Nascimento no jornal Diário de Notícias, do Rio de Janeiro, nos mostra a maneira que os oficiais atuavam 
Revista do Corpo Discente do Programa de Pós-Graduação em História da UnB

Em TEMPO dE HISTÓRIAS | Brasília-DF | n. 36 | p. 504-526 | jan./jun. 2020.

ISSN 2316-1191

[...] ter sofrido, na ocasião, uma série de pressões, sobretudo da parte do comandante Corrêa Pinto, que estivera em sua residência, com outro oficial". Afirmou ainda que "as autoridades responsáveis pelos inquéritos fizeram pressões para que ela assinasse uma declaração, admitindo o suicídio do marido. (COMISSÃO NACIONAL DA VERDADE, 2014, p.169) ${ }^{8}$

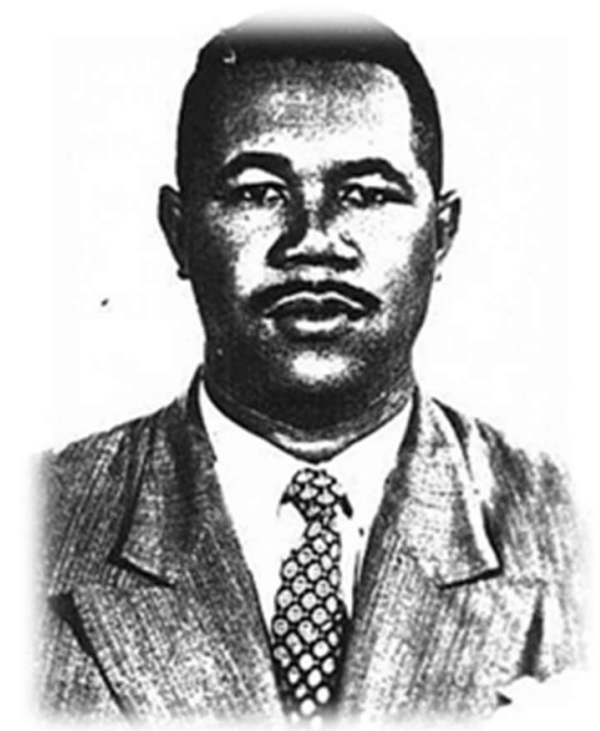

Imagem $\quad 1 \quad-\quad$ Dilermano Mello do $\quad$ Nascimento. Disponível em http://www.desaparecidospoliticos.org.br/

O segundo caso, também de um homem negro chamado Jorge Aprígio de Paula (Imagem 2). Nascido no Rio de Janeiro no dia 10 de fevereiro de 1938, era estudante do colegial e atuou no movimento estudantil de sua escola na época. Foi operário e faleceu no dia 1 de abril de 1968, dia conhecido como o dia nacional do protesto, onde Jorge estava participando de uma manifestação no centro do Rio de Janeiro, em repúdio a morte do estudante Edson Luís, ocorrida em março do mesmo ano. Jorge Aprígio de Paula foi atingido por um tiro nas costas e acabou morrendo no local.

Um trecho que consta em suas informações no relatório final da CNV é possível observar a dificuldade que a família de Jorge encontrou para que sua morte fosse assumida pelo Estado

A CEMDP indeferiu, em 7 de agosto de 1997, o pedido apresentado pela família de Jorge com a alegação de que não havia elementos que comprovem que as ruas da cidade onde ocorreram os fatos tenham se transformado em "dependência policial assemelhada". Em função de promulgação da Lei $\mathrm{n}^{0}$ 10.875/2004, ampliasse o escopo da legislação anterior e o caso é levado novamente em consideração, sendo deferido em 7 de dezembro de 2004. ( COMISSÃO NACIONAL DA VERDADE, 2014, p.235) ${ }^{9}$

\footnotetext{
${ }^{8}$ Disponível em http://www.cnv.gov.br/images/pdf/relatorio/volume_3_digital.pdf (p.169)

9 Disponível em http://www.cnv.gov.br/images/pdf/relatorio/volume_3_digital.pdf (p.235)
} 
Revista do Corpo Discente do Programa de Pós-Graduação em História da UnB Em TEMPO dE HISTÓRIAS | Brasília-DF | n. 36 | p. 504-526 | jan./jun. 2020.

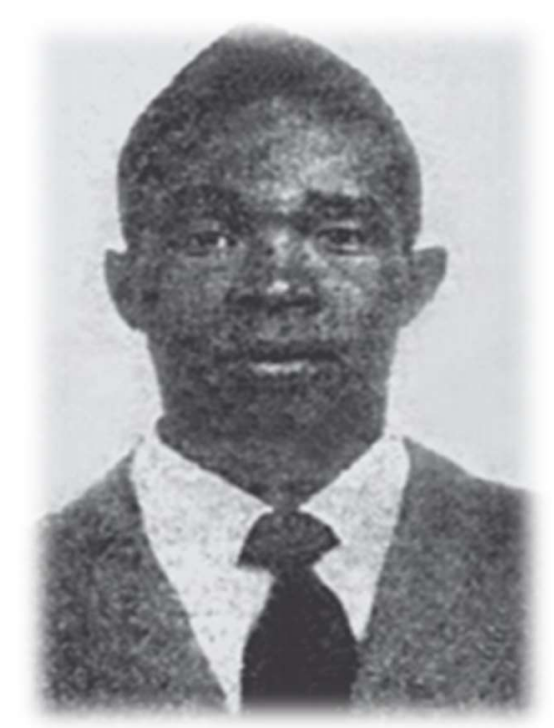

Imagem 2 - Jorge Aprígio de Paula. Disponível em http://www.desaparecidospoliticos.org.br/

Estes dois casos estão disponíveis no relatório final da Comissão Nacional da Verdade. A escolha para utilizá-los no artigo é justamente para demonstrar o modo que a repressão alcançava as pessoas negras, fomentado por um racismo institucionalizado e que apesar de ocuparem classes econômicas e sociais diferentes, foram vítimas pela truculência do Estado. A motivação de suas mortes ficou sem resolução, talvez pelo fato de ambos possuírem algo em comum: a cor da pele preta. O curioso destes dois casos é o fato de o relatório apontar que os dois homens não tinham qualquer ligação com partidos políticos ou organizações de esquerda e mesmo assim se tornaram vítimas da ditadura. Busquei por outras fontes ou produções sobre ambos os casos para acrescentar maiores informaões ao artigo e infelizmente nada encontrei sobre a trajetória destes homens, além do que está publicado no relatório.

Os dois casos apresentados acima deixam evidente que há uma problemática para encontrar fontes documentais sobre vítimas da ditadura civilmilitar, um reflexo das consequências de regimes autoritários, tornando difícil o acesso a documentos da época, deixando um lapso na história do Brasil e na busca por memória, verdade e justiça de vítimas e seus familiares. Dilermano e Jorge, militantes ou não tiveram suas vidas interrompidas pela violência e repressão do Estado.

No total de 434 mortos e desaparecidos presentes no relatório final da Comissão Nacional da Verdade, realizei um levantamento de 43 mortos e desaparecidos negras e negros presentes no documento. Nesta perspectiva resolvi traçar um perfil dessas pessoas, sobre os quais apresento alguns resultados e apresento algumas analises referente a alguns aspectos como: maior adesão a determinadas organizações políticas, quantidade de homens versus quantidade de mulheres, quantos são mortos versus quantos são desaparecidos, entre outros. 


\section{Filstistorias}

Revista do Corpo Discente do Programa de Pós-Graduação em História da UnB

Em TEMPO dE HISTÓRIAS | Brasília-DF | n. 36 | p. 504-526 | jan./jun. 2020.

ISSN 2316-1191

Quanto às organizações de esquerda que estes militantes atuavam, temos os seguintes resultados:

\begin{tabular}{|c|c|}
\hline Organizações de esquerda & Número de militantes \\
\hline Aliança Libertadora Nacional (ALN) & 6 \\
\hline Ação Popular (AP) & 2 \\
\hline Movimento Ação Revolucionária (MAR) & 1 \\
\hline Movimento Trabalhista Renovador (MTR) & 1 \\
\hline Marx, Mao, Marighella, Guevara (M3G) & 1 \\
\hline Partido Comunista do Brasil (PCdoB) & 10 \\
\hline Partido Comunista Brasileiro (PCB) & 7 \\
\hline Partido Comunista Brasileiro Revolucionário (PCBR) & 4 \\
\hline Partido Comunista Revolucionário (PCR) & 2 \\
\hline $\begin{array}{l}\text { Vanguarda Armada Revolucionária Palmares (VAR- } \\
\text { PALMARES) }\end{array}$ & 1 \\
\hline Vanguarda Popular Revolucionária (VPR) & 6 \\
\hline Federação Nacional dos Trabalhadores na Indústria Gráfica & 1 \\
\hline Ligas Camponesas & 1 \\
\hline
\end{tabular}


Revista do Corpo Discente do Programa de Pós-Graduação em História da UnB Em TEMPO dE HISTÓRIAS | Brasília-DF | n. 36 | p. 504-526 | jan./jun. 2020. ISSN 2316-1191

\begin{tabular}{|l|c|} 
Sindicatos & 3 \\
\hline Não Possui & 3 \\
\hline
\end{tabular}

Fonte: Relatório da Comissão Nacional da Verdade - 2014.

É importante lembrar que durante a realização deste levantamento de dados, surgiu o caso de 3 militantes atuarem em mais de uma organização política, logo o número total de organizações vai além do número total de 43 mortos e desaparecidos que mencionei acima.

As duas organizações que apresentam o maior número de militantes é o Partido Comunista do Brasil, com o total de 10 militantes. O PCdoB era um partido a finalidade de preparar trabalhadores para a luta armada no campo, como foi o caso da guerrilha do Araguaia, onde vários militantes que constam aqui nesta pesquisa atuaram nela. Logo, acredita-se que partidos como o PCdoB não tinha objetivo apenas de derrubar a ditadura civil-militar no país, mas também de incluir a construção de um projeto revolucionário para a sociedade brasileira, diferente dos outros partidos e organizações que possuíam uma ideologia mais pacífica, contra a luta armada, como é o caso do PCB, por exemplo, fez com que muitos companheiros rompam com o partido, criando outras organizações e partidos. O PCdoB foi fundado em fevereiro de $1962 \mathrm{em}$ conjunto com a publicação do "Manifesto Programa". ${ }^{10}$

O número elevado de militantes filiados ao Partido pode ser respondido por esse trecho que fala onde o partido atuou mais, falando especificamente da guerrilha do Araguaia, onde constam 3 militantes negros e negras no relatório. O trecho diz que diz:

O PCdoB participou das lutas sociais, entre 1962 e 1968, particularmente no movimento estudantil, e dirigiu a luta guerrilheira do Araguaia, entre 1972 e 1974, quando a guerrilha seria aniquilada. As forças guerrilheiras do Araguaia - FORGA - constituíam o ponto alto da vaga guerrilheira que agitou o país depois de 64. Suas ações, lutas e programa seriam divulgados pela revista "Araguaia", que circulou entre junho de 1974 e abril de 1975 (REIS; DE SÁ,1985, p.23).

Com relação ao número de homens e mulheres, temos o seguinte resultado:

10 Primeiro texto político publicado pelo novo PC do B, em fevereiro de 1962. 
Revista do Corpo Discente do Programa de Pós-Graduação em História da UnB

Em TEMPO dE HISTÓRIAS | Brasília-DF | n. 36 | p. 504-526 | jan./jun. 2020.

ISSN 2316-1191

\begin{tabular}{|c|c|}
\hline Homens & Mulheres \\
\hline 38 & 5 \\
\hline
\end{tabular}

Fonte: Relatório da Comissão Nacional da Verdade - 2014.

O número inferior de mulheres com relação aos homens é uma problemática bastante delicada, pelo fato do histórico da mulher negra na sociedade e por seu corpo passar por um duplo fenômeno: o do racismo e do sexismo, que segundo Lélia Gonzalez

Como todo mito, o da democracia racial oculta algo para além daquilo que mostra. Numa primeira aproximação, constatamos que exerce sua violência simbólica de maneira especial sobre a mulher negra. Pois o outro lado do endeusamento carnavalesco ocorre no cotidiano dessa mulher, no momento em que ela se transfigura na empregada doméstica. É por aí que a culpabilidade engendrada pelo seu endeusamento se exerce com fortes cargas de agressividade. É por aí, também, que se constata que os termos mulata e doméstica são atribuições de um mesmo sujeito. A nomeação vai depender da situação em que somos vistas (GONZALES, 1984, p.228).

O número significativo de apenas 5 mulheres negras constarem na lista de mortos e desaparecidos ao relatório da Comissão Nacional da Verdade deixa evidente a importância que suas histórias sejam abordadas neste artigo, para que a trajetória política de luta e resistência das mulheres e em especial aqui, as mulheres negras à ditadura civil-militar brasileira não sejam esquecidas.

A primeira a ser apresentada se chama Alceri Maria Gomes da Silva (Imagem 3), gaúcha, começou sua atuação na política no movimento operário, por trabalhar num escritório de uma fábrica, em seguida filiando-se ao sindicato dos metalúrgicos. Mudou-se para São Paulo, para engajar-se na luta contra a ditadura civil-militar, onde se filiou a VPR. Alceri é uma vítima desaparecida desde $1970 .{ }^{11}$

11 Relatório completo disponível na versão final do Relatório da Comissão Nacional da verdade 2014 (p. 491). 
Revista do Corpo Discente do Programa de Pós-Graduação em História da UnB Em TEMPO dE HISTÓRIAS | Brasília-DF | n. 36 | p. 504-526 | jan./jun. 2020.

Figura 3 - Alceri Maria Gomes da Silva. Disponível em http://www.desaparecidospoliticos.org.br/

Helenira Resende de Souza Nazareth (Imagem 4), mais conhecida como Preta, paulista do interior, começou sua vida na política muito cedo, no ensino médio onde foi uma das fundadoras do grêmio estudantil. Logo em seguida ingressou no curso de Letras da USP, foi vice-presidente da UNE e militante do $\mathrm{PC}$ do B. Viveu na clandestinidade após ser presa pela terceira vez, quando resolveu migrar-se de cidade em cidade até mudar-se definitivamente para o Araguaia. $\mathrm{O}$ que se sabe sobre sua morte é que ela caiu numa emboscada com alguns de seus companheiros. Seus restos mortais ainda se encontram desaparecidos, colocando Helenira como mais uma vítima desaparecida da ditadura civil-militar. ${ }^{12}$

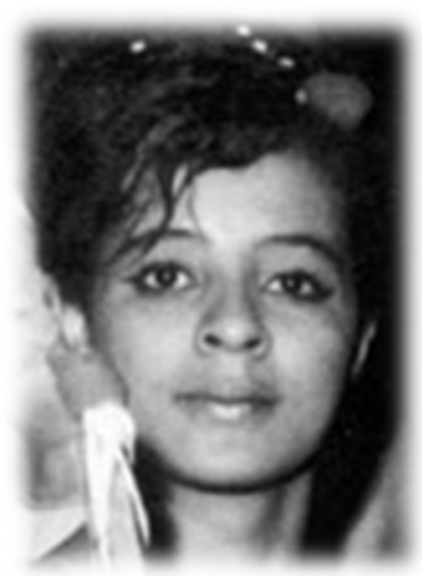

Imagem 4 - Helenira Resende de Souza Nazareth. Disponível em http://www.desaparecidospoliticos.org.br/

Lucia Maria de Souza (Imagem 5), nascida em São Gonçalo, família de origem pobre, começou a trabalhar desde muito jovem e através de seu trabalho financiou seus estudos, ingressando na Escola de Medicina e Cirurgia do Rio de

12 Relatório completo disponível na versão final do Relatório da Comissão Nacional da verdade 2014 (p.1028). 
Revista do Corpo Discente do Programa de Pós-Graduação em História da UnB Em TEMPO dE HISTÓRIAS | Brasília-DF | n. 36 | p. 504-526 | jan./jun. 2020. ISSN 2316-1191

Janeiro entre os anos de 1969 e 1970. Fazia parte do comitê universitário do PCdoB, encarregada da Secretaria de Agitação e Propaganda, cuja responsabilidade principal era a edição do jornal A Luta. Em 1971 mudou-se para a região do Araguaia para ingressar na guerrilha armada. O corpo de Lucia está desaparecido até os dias atuais. ${ }^{13}$

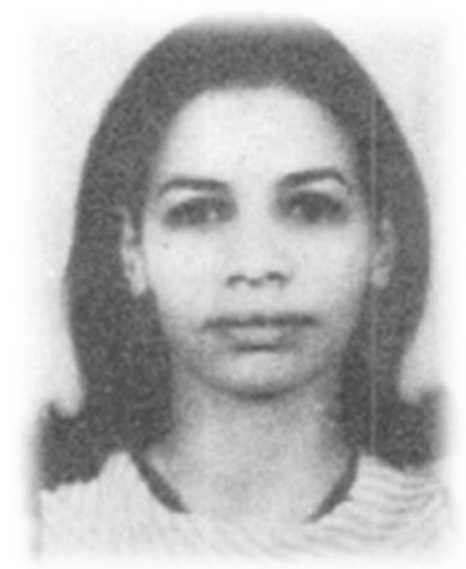

Imagem 5 - Lucia Maria de Souza. Disponível em http://www.desaparecidospoliticos.org.br/

Dinalva Conceição Oliveira Teixeira (Imagem 6), baiana, geóloga formada na Universidade Federal da Bahia (UFBA), foi moradora da casa do estudante, participando ativamente do movimento estudantil entre os anos de 1967 e 1968. Mudou-se para o Rio de Janeiro em 1969 quando se casou e começou a trabalhar no Ministério de Minas e Energia além de pertencer a Sociedade Brasileira para o Progresso da Ciência (SBPC). Dinalva e o esposo foram para o Araguaia, onde lá ela teve grande atuação por fazer parte do destacamento C, como vicecomandante. Foi uma das guerrilheiras mais respeitadas e admiradas da região do Araguaia e a única mulher a ocupar o cargo de vice-presidente da guerrilha d Araguaia. Seu corpo se encontra desaparecido, sendo ela uma vítima desaparecida da ditadura civil-militar. ${ }^{14}$

13 Relatório completo disponível na versão final do Relatório da Comissão Nacional da verdade 2014 (p.1361).

${ }^{14}$ Relatório completo disponível na versão final do Relatório da Comissão Nacional da verdade 2014 (p.1678). 
Revista do Corpo Discente do Programa de Pós-Graduação em História da UnB Em TEMPO dE HISTÓRIAS | Brasília-DF | n. 36 | p. 504-526 | jan./jun. 2020.

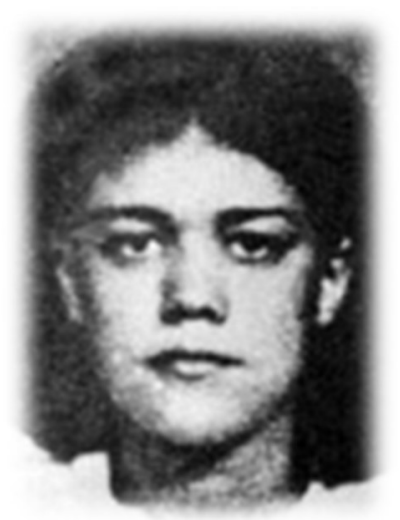

Imagem 6 - Dinalva Conceição Oliveira Teixeira. Disponível em http://www.desaparecidospoliticos.org.br/

Ieda Santos Delgado (Imagem 7), carioca, formada em Ciências Jurídicas e Sociais pela Universidade de Brasília (UNB). Era funcionária do departamento Nacional de produção Mineral do Ministério de Minas e Energia no Rio de Janeiro e estava prestes a ser transferida para Brasília onde atuaria como secretária jurídica do Centro de Pesquisas Experimentais. Era militante da ALN e desapareceu no dia 11 de abril de 1974, aos 28 anos. Ieda Santos Delgado é uma vítima desaparecida em virtude das ações dos agentes do Estado. ${ }^{15}$

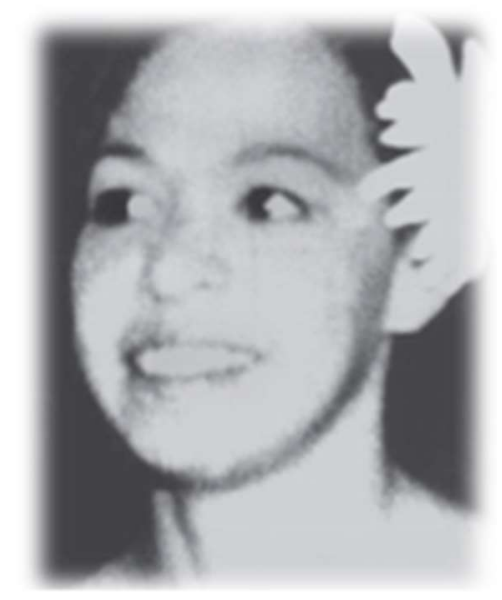

Imagem 7 - Ieda Santos Delgado. Disponível em http://www.desaparecidospoliticos.org.br/

Médicas, advogadas, operárias, professoras, geólogas, todas tiveram seu papel importante na luta contra a repressão no país. Por coincidência ou não, todas as cinco mulheres são vítimas desaparecidas, ou seja, seus corpos não foram encontrados até o momento da realização desta pesquisa. Logo as trajetórias dessas mulheres são indispensáveis para que se tenha a dimensão que mulheres negras estavam em ação e resistência contra a ditadura civil-

15

Relatório completo disponível na versão final do Relatório da Comissão Nacional da verdade 2014 (p.1642). 


\section{Filstistorias}

Revista do Corpo Discente do Programa de Pós-Graduação em História da UnB

Em TEMPO DE HISTÓRIAS | Brasília-DF | n. 36 | p. 504-526 | jan./jun. 2020.

ISSN 2316-1191

militar e que esta pesquisa faz questão de visibilizá-las da maneira que merecem.

Com relação à faixa etária dos militantes negros e negras, apresento os seguintes resultados:

\begin{tabular}{|c|c|}
\hline Idade & Resultado \\
\hline De $18-30$ anos & 19 \\
\hline De $31-50$ anos & 20 \\
\hline Acima de 50 anos & 3 \\
\hline
\end{tabular}

Fonte: Relatório da Comissão Nacional da Verdade (2014)

Com relação ao nível de escolaridade destas/es mortas/os e desaparecidas/os, apresento os seguintes resultados:

\begin{tabular}{|c|c|}
\hline Escolaridade & Resultado \\
\hline Ensino fundamental completo & 1 \\
\hline Ensino fundamental incompleto & 1 \\
\hline Ensino médio completo & 6 \\
\hline Ensino médio incompleto & 3 \\
\hline Ensino superior completo & 9 \\
\hline Ensino superior incompleto & 9 \\
\hline Não consta & 14 \\
\hline
\end{tabular}

Fonte: Relatório da Comissão Nacional da Verdade - 2014. 


\section{Filstistorias}

Revista do Corpo Discente do Programa de Pós-Graduação em História da UnB

Em TEMPO DE HISTÓRIAS | Brasília-DF | n. 36 | p. 504-526 | jan./jun. 2020.

ISSN 2316-1191

Referente à atuação profissional dessas/es mortas/os e desaparecidas/os, mostro os seguintes resultados:

\begin{tabular}{|c|c|}
\hline Atuação profissional & Resultado \\
\hline Advogada/o & 3 \\
\hline Ascensorista & 1 \\
\hline Camponês/a & 1 \\
\hline Deputada/o & 1 \\
\hline Escriturária/o & 1 \\
\hline Estudante & 11 \\
\hline Funcionária/o Pública/o & 2 \\
\hline Geóloga & 1 \\
\hline Grafista & 1 \\
\hline Jornalista & 1 \\
\hline Marinheiro & 2 \\
\hline Mecânico & 1 \\
\hline Militar & 1 \\
\hline Operária/o & 8 \\
\hline
\end{tabular}


Revista do Corpo Discente do Programa de Pós-Graduação em História da UnB

Em TEMPO dE HISTÓRIAS | Brasília-DF | n. 36 | p. 504-526 | jan./jun. 2020.

\begin{tabular}{|c|c|}
\hline Sargento & 2 \\
\hline Sapateiro & 1 \\
\hline Trabalhador rural & 2 \\
\hline Vereador & 1 \\
\hline Sem atuação profissional & 1 \\
\hline Não consta & 1 \\
\hline
\end{tabular}

Fonte: Relatório da Comissão Nacional da Verdade - 2014.

Baseado nos resultados das atuações profissionais das/os mortas/os e desaparecidas/ resultou em uma grande concentração de trabalhadoras e trabalhadores atuantes em trabalhos manuais ou que não exigem uma profissionalização específica. Este resultado mostra o reflexo da herança de um período escravista no país e da dificuldade da população negra em ocupar cargos profissionais de maior relevância ou com uma capacitação profissional para a função.

Com relação ao número de mortas/os e número de desaparecidas/os, com base nos resultados do relatório da Comissão Nacional da Verdade, apresento os seguintes resultados:

\begin{tabular}{|c|c|}
\hline Mortos & Desaparecidos \\
\hline 23 & 19 \\
\hline
\end{tabular}

Fonte: Relatório da Comissão Nacional da Verdade (2014).

Pude observar que os desaparecimentos começaram a surgir com mais frequência após AI-5, principalmente a partir dos anos de 1970 em diante. Acredito que seja por conta do aumento da repressão do Estado diante dos militantes e organizações políticas de esquerda. O historiador Marcos Napolitano aborda a questão os aspectos que desencadearam um maior número de vítimas neste período da ditadura civil-militar brasileira 
Revista do Corpo Discente do Programa de Pós-Graduação em História da UnB

Em TEMPO dE HISTÓRIAS | Brasília-DF | n. 36 | p. 504-526 | jan./jun. 2020.

ISSN 2316-1191

\begin{abstract}
Quando examinamos a lista de mortos e desaparecidos pela ditadura, notamos um dado inovador na história brasileira. Via de regra, as repressões e revoltas armadas no Brasil eram ferozes com os de baixo e moderadas com os de cima. A prisão e o exílio eram reservados às lideranças rebeldes vindas da elite ou das classes médias superiores. A repressão aos grupos de oposição entre 1969 e 1974 não poupou ninguém. Um dado indicativo da composição social da guerrilha e da repressão é a formação escolar. Dos 17.420 processados pela justiça militar que compõe a base do arquivo "Brasil Nunca Mais", 58\% tinham formação superior, completa ou incompleta, e 16\% tinha ensino secundário. (NAPOLITANO, 2014, p.127)
\end{abstract}

O levantamento foi realizado com o intuito de mostrar de forma breve quem foram essas/es militantes negras e negros presentes no relatório final da Comissão Nacional da Verdade, apresentando suas trajetórias políticas e pessoais quando possível. Para a historiografia do negro no Brasil, creio que estas reflexões e discussões abordadas no artigo auxiliem e instiguem outras e outros pesquisadoras/res, para que seja possível aprofundar e avançar no debate sobre raça e ditadura brasileira.

\title{
Considerações finais
}

O trabalho da Comissão Nacional da Verdade faz questão de tornar público a localização dos documentos de cada caso, como estão nomeados e etc. Para fins de pesquisas futuras, acaba tornando possível e facilita o acesso à informação e aos documentos da ditadura civil-militar que até hoje são documentos de acesso restrito, em alguns casos. Além disso, o relatório nos apresenta referências bibliográficas de materiais que foram produzidos e que consequentemente serviram para auxiliar na averiguação dos casos, bem como materiais midiáticos como jornais da época, revistas, que para historiadoras e historiadores são elementos fundamentais para a realização da pesquisa.

A abordagem da população negra na ditadura civil-militar não estar em evidência ou ser a preocupações de pesquisadoras e pesquisadores das Ciências Humanas se apresenta como uma lacuna evidente que precisa ser sanada, provado que pessoas negras eram alvo da pacificação do Estado, como uma alternativa de eliminar estas pessoas que desde momentos anteriores da História no país são alvos de extermínio como forma de colocar e estabelecer uma ordem utópica. No Brasil, práticas de pacificação e extermínio da população negra são denunciadas desde o período escravocrata e se intensificou no pós-abolição, com criações de leis de vadiagem, políticas de higienização, etc., sempre dando um jeito para eliminar este corpo apresentado como ameaça, inimigo e que precisa ser combatido.

Nesse sentido a escolha da não abordagem de uma breve apresentação e contextualização das violações de direitos humanos a população negra no relatório final da Comissão Nacional da Verdade é uma perda grande de para a contribuição a memória verdade e justiça às vítimas pretas da ditadura civil- 
Revista do Corpo Discente do Programa de Pós-Graduação em História da UnB Em TEMPO dE HISTÓRIAS | Brasília-DF | n. 36 | p. 504-526 | jan./jun. 2020. ISSN 2316-1191

militar brasileira, visto que algumas Comissões Estaduais da Verdade do país apresentaram estas questões referente as/os negras/os, como foi citado e utilizado como material de consulta para a produção deste artigo.

O Relatório da Comissão Nacional da Verdade vem com o objetivo de trazer memória, verdade e justiça aos familiares de mortos e desaparecidos em decorrência da ação do Estado. É evidente que muitas lacunas ainda estão sem respostas, mas para um país como o Brasil, é de suma importância que esta parte da história esteja tomando um rumo e que os devidos culpados sejam penalizados de alguma forma, mesmo que seja com seus nomes divulgados em documentos públicos como responsáveis por 434 mortes e desaparecimentos, não importa quanto tempo tenha passado.

\section{Referências}

Fontes Primárias

COMISSÃO, Nacional da Verdade. Relatório Final. Brasília, 2014.

COMISSÃO, Da Verdade do Estado de São Paulo "Rubens Paiva". Verdades Abertas. São Paulo, 2015.

Artigos e Livros

DOMINGUES, Petrônio. Fios de Ariadne: o protagonismo negro no pós-abolição. Revista Anos 90, Porto Alegre, v.6, n.30, p. 215-250, 2009.

FICO, Carlos. Violência, trauma e frustração no Brasil e na Argentina: o papel do historiador. Topoi (Rio de Janeiro), v. 14, n. 27, p. 239-261, 2013.

GASPAROTTO, Alessandra. Apontamentos (e desapontamentos) em relação à criação da Comissão Nacional da Verdade no Brasil. In: PADRÓS, Enrique Serra (org.). Cone Sul em tempos de ditadura: reflexões e debates sobre a História Recente. Porto Alegre: [s. e.], 2013.

GONZALEZ, Lélia; HASENBALG, Carlos Alfredo. Lugar de negro. Editora Marco Zero, 1982.

GONZALEZ, Lélia. Racismo e Sexismo na Cultura Brasileira. Revista Ciências Sociais Hoje, Anpocs, p. 223-244, 1984.

GONZALEZ, Lélia. A juventude negra brasileira e a questão do desemprego. Rio de Janeiro: UFRJ, 1979.

GORENDER, Jacob. Combate nas trevas. 5. ed. São Paulo: Fundação Perseu Abramo: Expressão Popular, 2014. 
Revista do Corpo Discente do Programa de Pós-Graduação em História da UnB Em TEMPO dE HISTÓRIAS | Brasília-DF | n. 36 | p. 504-526 | jan./jun. 2020. ISSN 2316-1191

MOORE, Carlos. Racismo e sociedade: novas bases epistemológicas para entender o racismo. - Belo Horizonte, Mazza Edições, 2007.

MOURA, Clóvis. O racismo como arma de dominação. Revista Princípios. Ed. 34, Ago/Set/Out, p. 28- 38, 1994.

NASCIMENTO, Abdias. O genocídio do negro brasileiro: processo de um racismo mascarado. Editora Perspectiva SA, 2016.

NAPOLITANO, Marcos. 1964: história do regime militar brasileiro. São Paulo: Contexto, 2014.

PADROS, Enrique Serra. Terrorismo de Estado: reflexão a partir das experiências das ditaduras de Segurança Nacional. In: GALLO, Carlos Artur (org); RUBERT, Silvania (org). Entre a memória e o esquecimento: estudos sobre os 50 anos do golpe civil-militar no Brasil. Porto Alegre: Deriva, 2014, p. 13-36.

PINTO, Simone Rodrigues. Direito à memória e à verdade: comissões de verdade na América Latina. Revista Debates, v. 4, n. 1, p. 128, 2010.

REIS FILHO, Daniel Aarão; DE SÁ, Jair Ferreira. Imagens da revolução: documentos políticos das organizações clandestinas de esquerda dos anos 1961 a 1971. Marco Zero, 1985.

REIS, Daniel Aarão. 1964: golpe militar ou civil?. In: FIGUEIREDO, Luciano (org). História do Brasil para ocupados. Rio de Janeiro: Casa da Palavra, 2013, p. 197-201.

Ditadura e democracia no Brasil. Rio de Janeiro: Zahar, 2014. 